Review Article

\title{
Periodontal Biological Events Associated with Orthodontic Tooth Movement: The Biomechanics of the Cytoskeleton and the Extracellular Matrix
}

\author{
L. Feller, ${ }^{1}$ R. A. G. Khammissa, ${ }^{1}$ I. Schechter, ${ }^{2}$ A. Moodley, ${ }^{1}$ \\ G. Thomadakis, ${ }^{3}$ and J. Lemmer ${ }^{1}$ \\ ${ }^{1}$ Department of Periodontology and Oral Medicine, Sefako Makgatho Health Sciences University, Pretoria 0204, South Africa \\ ${ }^{2}$ Schulich Faculty of Chemistry, Technion-Israel Institute of Technology, 32000 Haifa, Israel \\ ${ }^{3}$ Private Practice, 15 School Road, Morningside, Johannesburg 2057, South Africa \\ Correspondence should be addressed to L. Feller; liviu.feller@smu.ac.za
}

Received 5 June 2015; Accepted 21 July 2015

Academic Editor: Shanfeng Wang

Copyright @ 2015 L. Feller et al. This is an open access article distributed under the Creative Commons Attribution License, which permits unrestricted use, distribution, and reproduction in any medium, provided the original work is properly cited.

\begin{abstract}
The mechanical stimuli generated by orthodontic forces cause deformation of extracellular matrices and cells, vascular changes, inflammation, and the release of active biological agents generating a complex multifactorial sequence of biological events culminating in bone remodelling enabling orthodontic tooth movement. Orthodontic forces on the teeth generate stresses in periodontal tissues according to a number of variables including the type (continuous, interrupted, or intermittent), magnitude, direction, and frequency of the applied load. Whether the strain is compressive or tensile determines whether bone deposition or bone resorption will occur. The mechanically induced strains mediate structural changes in extracellular matrices and in cells, consequently affecting cellular gene expression and function. In the extracellular matrix, mechanosensing molecules integrated into the structure of various proteins can be activated upon load-induced protein unfolding. These specialized molecules have the capacity to sense and then to convert microenvironmental biomechanical stimuli into intracellular biochemical signals that interact to generate a coordinated tissue response. It is also possible that the applied force may directly cause nuclear deformation with configurational changes in chromatin, thus influencing gene expression. In this review article we summarize the current general concepts of mechanotransduction influencing the remodelling of periodontal tissues thus enabling tooth movement in response to applied orthodontic loads.
\end{abstract}

\section{Introduction}

Orthodontic forces applied to teeth generate complex mechanical loading patterns comprising compressive, tensile, and shear strains which in turn elicit diverse and complex biological responses in the periodontal tissues immediately surrounding the loaded teeth [1]. These mechanically induced tissue strains are determined by a number of variables including the type of force (i.e., continuous, interrupted, and intermediate), the magnitude, direction, location, and frequency of the load applied $[1,2]$; the shapes, number, lengths, locations, and angulations of the mechanically loaded teeth [3]; and the material properties of the local periodontal ligament and alveolar bone $[3,4]$.
In the context of orthodontic tooth movement, for purposes of convenience, one can identify two distinct zones in the periodontal ligament and associated alveolar bone: a zone where the periodontal ligament and adjacent alveolar bone are compressed and a zone where the tissues are under tension $[1,2,5]$. Although it is an oversimplification, the response to applied orthodontic forces is bone formation on the tension side and bone resorption on the compression side $[1,2$, $5]$. The net outcome of this tissue remodelling is tooth movement $[2,6]$.

In general, compressive and tensile stresses induce both directly and indirectly the release of specific active signaling molecules/biological agents by a variety of local cells including fibroblasts, macrophages, cementoblasts, osteoblasts, 
osteoclasts, and cells of the local vasculature [1,7]. These specific agents are differentially expressed at various sites around the mechanically loaded teeth and mediate the dynamic tissue responses involved in tooth movement.

However, despite this differential expression of tissue remodelling agents, it appears that, as in other complex systems, the level of expression of a specific agent and its interaction with other biologically active agents in the microenvironment, rather than merely the type of the agent, are important in determining the biological outcomes of bone resorption and bone formation [1]. A complex system of diverse interacting agents will have many interactions, the behaviour of each agent influenced by the other agents. The aggregate of the integrated activity of the several interacting biological agents is not one of simple cause and effect behavior and therefore cannot be derived from summation of the activity of the individual agents [8-10].

The biologically active agents released into the local microenvironment by the cells mentioned above in response to load-induced strains comprise cytokines, neurotransmitters, matrix metalloproteinases, growth factors, and bone proteins including tumour necrosis factor- $\alpha$ (TNF- $\alpha$ ), receptor activator of nuclear factor- $\kappa \mathrm{B}$ ligand (RANKL), osteoprotegerin (OPG), interleukin-10 (IL-10), IL-6, IL-1 $\beta$, endothelins, prostaglandins, osteocalcin, vascular endothelial growth factor (VEGF), macrophage-colony stimulating factor (MCSF), osteopontin, and collagen $1[1,5-7,11,12]$. Some of these active agents are proinflammatory mediators generating a transitional, aseptic inflammatory response triggering the process of tissue remodelling. An inflammatory element is thus essential for orthodontic tooth movement $[1,11,13,14]$.

\section{Stages of Orthodontic Tooth Movement}

In general it appears that greater orthodontic forces generating higher magnitudes of stresses promote significant tissue necrosis and hyalinization $[12,15]$, and tooth movement can occur only at the expense of undermining bone resorption and a hypoxically degenerated periodontal ligament $[11,16]$. On the other hand, lower orthodontic forces generating lower magnitudes of stress are associated with little or no tissue necrosis and hyalinization. Under these circumstances, direct frontal resorption of the alveolar bone and remodelling of the vascular and fibrous elements of the periodontal ligament will allow continuous steady tooth movement with no significant lag phase $[12,15]$. However, in practice, some degree of undermining resorption is unavoidable.

This said, three stages of orthodontic tooth movement have been described. Stage one (initial stage) lasts about 24 to 48 hours and is characterized by tooth displacement in the periodontal ligament space within its bone socket. Stage two (lag stage) lasts 20-30 days and is characterized by the formation of necrosis and hyalinization in response to compression of the vasculature and subsequent hypoxia in the periodontal ligament and adjacent alveolar bone [5, 11, 16-19]. The hyalinized tissue is not only found in the compression zone ahead of the moving tooth but also lingually and buccally caused by local morphological variations of tooth and alveolar bone [16]. The hyalinized tissue is removed by macrophages and multinucleated giant cells and the necrotic bone by undermining resorption $[16,19,20]$. In this lag stage there is little or no tooth movement $[5,17]$.

In stage 3 , the postlag stage, there is tooth movement mediated by bone remodelling through the agency of osteoclasts and osteoblasts on a background of neoangiogenesis. The neoangiogenesis is predominantly mediated by hypoxiainducible factor-1 (HIF-1) and VEGF, but also by other biological agents including fibroblast growth factor (FGF), $\mathrm{TNF} \alpha$, and transforming growth factor (TGF) $\beta[5,19,20]$.

There is substantial variation in the rate of tooth move ment in different but comparable subjects in response to apparently identical orthodontic forces. This strongly suggests that polymorphism of genes encoding cytokines and other subject-specific factors influence the biological responses to similar orthodontic forces [15].

\section{Stress, Strain, and the Cytoskeleton}

In continuum mechanics, deformation is defined as transformation of a material body (e.g., the position of all body particles) from a reference configuration to its current configuration [21]. Strain is a measure of deformation representing the displacement of particles in the body relative to their reference locations. Deformations which revert to the reference configuration after the stresses have been removed are termed elastic deformations while plastic, viscous, and desmoplastic deformations are irreversible and occur when the stresses applied exceed the elastic limit of the body material [22]. In this regard, viscoelastic material is one that displays both viscous and elastic properties when it undergoes deformation. On the other hand stiffness can be defined as the resistance to deformation exhibited by an elastic body material in response to the applied force $[22,23]$, while the reverse of the stiffness is termed compliance or flexibility [24].

The cytoskeleton is a dynamic structure comprising three main polymeric elements, microtubules, actin filaments, and intermediate filaments, organized in a network that provides resistance to stress-induced deformation. The architecture of the structure determines the mechanical behaviour of the cytoskeleton and the physical properties of the cell. The cytoskeleton generates, transmits, and responds to both internal and external mechanical stresses, and through the cytoskeletal network mechanical stimuli mediate cell shape, motility, differentiation, survival, and ultimately cell behaviour. In response to applied forces, the cytoskeletal network stiffens, thus resisting additional deformation, and reorganizes in order to maintain the cellular integrity [25].

The intermediate filaments are the least stiff of the cytoskeletal components and therefore withstand tensile and sheer stresses more efficiently than do microtubules and actin filaments [26]. In response to mechanical stresses, assembly and integration of additional intermediate filaments take place, which then interconnect with each other and with actin filaments and microtubules, contributing to the structural integrity of the cell [25].

On the other hand, the microtubules are by far the stiffest cytoskeletal component [25] and therefore cannot withstand large tensile or shear stresses without exhibiting deformation, 
but they can resist large compressive stresses and thus contribute to the stability of the cytoskeleton and of the cell shape [26].

Although actin filaments are less stiff than microtubules, a high concentration of molecular crosslinks increases their stiffness, and networks of highly branched actin filaments can generate the forces associated with changes in cell shape, and with cell motility [25]. They withstand more efficiently tensile or shear stresses than do microtubules [26]. Cross-bridging interaction between cytoskeletal actin and myosin filaments generate contractile forces which are transmitted to the extracellular matrix as traction forces, causing strains in the extracellular matrix, which consequently may become stiffer [27].

Cells adhere to, and pull on their extracellular matrix in a way that is related to the degree of stiffness of the matrix [27]. Stiff matrices induce strains at the cellular focal adhesions with consequent strong cell adhesion to the extracellular matrix. Conversely, flexible matrices do not have the capacity to generate the necessary required stress at focal adhesion sites for the development of mature fully functional focal adhesions [22]. In this regard, it has been shown that undifferentiated mesenchymal progenitor cells will differentiate into distinct lineages according to the stiffness characteristic of their microenvironmental matrices [22], and these variations in stiffness of the microenvironmental extracellular matrices also influence cell shape [22].

Extracellular mechanical stresses can activate cell membrane integrins and focal adhesion molecules triggering the assembly of contractile actin-filamentary bundles, termed "stress fibers" [25]. These stress fibers form intracellularly at the cell adhesion-extracellular contact sites in response to elevated mechanical stresses, generating contractile forces [26].

The contractile activity of the actin-myosin cytoskeleton is usually inwardly directed towards the center of the cell. This activity may be induced either by extracellular matrix stresses or stiffness, or by intracellular forces. These contractile forces can activate intracellular signaling pathways that regulate gene expression, cell morphology, and ultimately cell function [22].

In the context of orthodontic tooth movement, orthodontic load-induced compressive, tensile or shear stresses cause dynamic alterations within the extracellular matrix and within the cytoskeleton of cells, in the local microenvironment. The stress-induced strain mediates the proliferation, differentiation, motility, and morphology of osteoblasts, osteoclasts, and other cells in the periodontal ligament and in the alveolar bone, as well as the production of cytokines and growth factors. All these together determine the balance between bone resorption and formation, thus ultimately influencing local tissue remodelling that allows tooth movement in response to applied orthodontic loads.

\section{Extracellular Matrix (ECM) in relation to Orthodontic Tooth Movement}

The extracellular matrix is a complex structure of interacting molecules forming a physical microenvironment of a threedimensional mesh-like fibrous scaffold, and its biochemical makeup, architecture, and mechanical properties are all essential elements contributing to the determination of physiological responses and function and of survival of cells. Cell anchorage and the vector of cell migration are determined by the fibrous element of the extracellular matrix [11, 28-31].

Cells adhere to the extracellular matrix by focal adhesion domains at the cell plasma membrane. These domains are localised multifunctional dynamic protein complexes comprising transmembrane integrins and cytoplasmic proteins including focal adhesion kinase (FAK), Src, paxillin, tensin, and filamin, linking the cytoskeleton to extracellular matrix proteins including fibronectin, vitronectin, and collagen (Figure 1). These focal adhesion domains mediate reciprocal interactions between the extracellular matrix and the cell and influence the assembly and remodelling of the extracellular matrix on one hand and cell adhesion, migration, proliferation, differentiation, function, and apoptosis on the other hand (Figure 1) [4, 22, 23, 32].

Biochemically stressed extracellular matrix promotes integrin clustering and activation and assembly of focal adhesion proteins and induces Rho pathway-mediated cell contractility. The small G-protein Rho, a member of the Rho family of small guanosine triphosphatases (GTPase), is an important regulator of cytoskeletal tension (Figure 1). Through Rho-associated kinase (ROCK), activated Rho enhances polymerization of myosin light-chains and subsequently cross-bridging interactions between cytoskeletal actin and myosin filaments, mediating the development of stress fibers and increasing cytoskeletal tension and contractility. This in turn upregulates intracellular signalling pathways associated with cell cycle progression and thus promotes cell proliferation. Through the Rho-ROCK pathway, stiff extracellular matrices or external loads further promote formation of stress fibers, integrin clustering, and focal adhesion reinforcement, with a positive impact on cell-matrix adhesion [22, 27, 3234].

Integrins and other proteins in focal adhesion domains act as cellular mechanosensors. Upon application of force, the stress that develops in the matrix and the consequent strain upon the mechanosensors triggers intracellular signals that control transcription factors determining gene expression. The activated genes regulate cell adhesion, migration, proliferation, apoptosis, and thus ultimately the response to the initial mechanical stress (Figure 2) [28, 31, 35-37]. Fibroblasts, osteoblasts, and osteocytes in the periodontium thus react to the applied loads of orthodontic treatment via the sequence of stress, strain including that related to fluid flow, and the production of biological mediators culminating in tissue remodelling [4].

Mechanical loads from application of orthodontic forces will stretch all the proteins of the extracellular matrix and the resulting configurational changes within the highly polymorphic protein structure can expose or hide molecular recognition sites, with inevitable cell activation and consequent modulation of cell responses $[32,35,36]$. In a stressed extracellular matrix, tensional forces exerted upon the cell by the matrix will cause intracellular isometric tension, further inducing configurational changes and exposure of hidden 


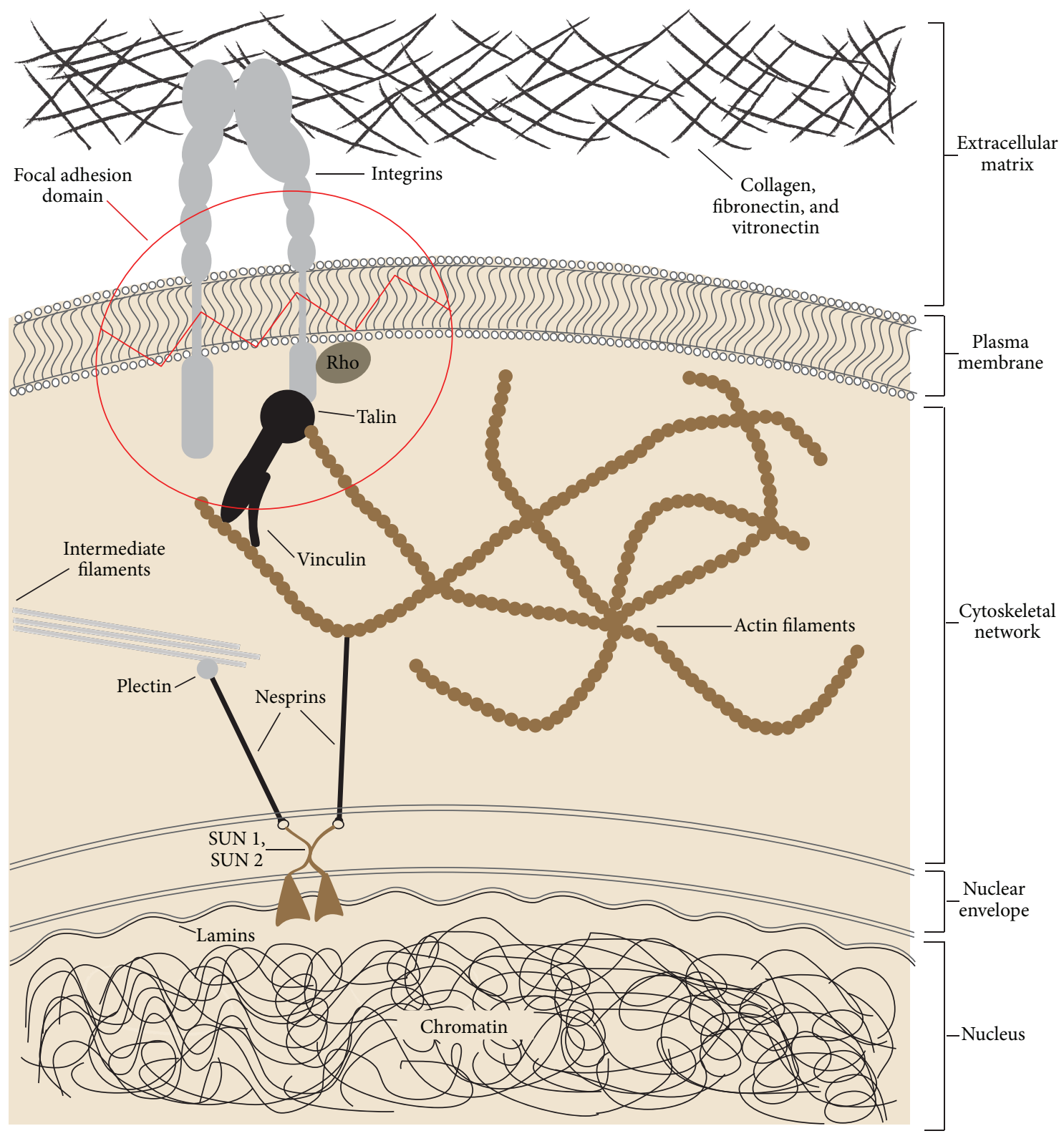

FIGURE 1: Focal adhesions are protein complexes which connect extracellular matrix proteins such as collagen, fibronectin, and vitronectin to the intracellular actin cytoskeleton by way of integrins and talin. The extracellular matrix derived strain causes configurational changes in the focal adhesion protein talin, exposing vinculin-binding molecular sites. This results in recruitment of vinculin leading to reinforcement of the focal adhesions and establishing a physical link between extracellular matrix and the nuclear envelope through the agency of the integrin-talin/vinculin-actin filament molecular chain. This chain of linked molecules ultimately transmits signals from the mechanically stressed extracellular matrix to the nucleus via the nuclear envelope lamins, nesprins, SUN1, and SUN2. Rho GTPase regulates cytoskeletal organization and in response to extracellular mechanical stimuli, Rho activation promotes myosin contractility and induces the reinforcement of focal adhesions $[22,23,32]$.

recognition molecules of some extracellular matrix proteins (Figure 3) [22, 31, 36, 37].

Therefore, a positive feedback loop is generated with extracellular matrix forces inducing intracellular stresses and regulating cell function and the intracellular cytoskeletally generated forces reciprocally influencing extracellular matrix biomechanics, function, and remodelling [38]. The strains developed in focal adhesions are thus generated by both intracellular contractile stresses and the stiffness of the extracellular matrix [22].

Intracellular strain resulting from stress in the extracellular matrix has the capacity to promote assembly of focal adhesions and clustering of integrins with their structural reinforcement and strengthening $[35,39]$ and to induce configurational alterations in some cytoskeletal filaments and crosslinks or in motor proteins, influencing intracellular 


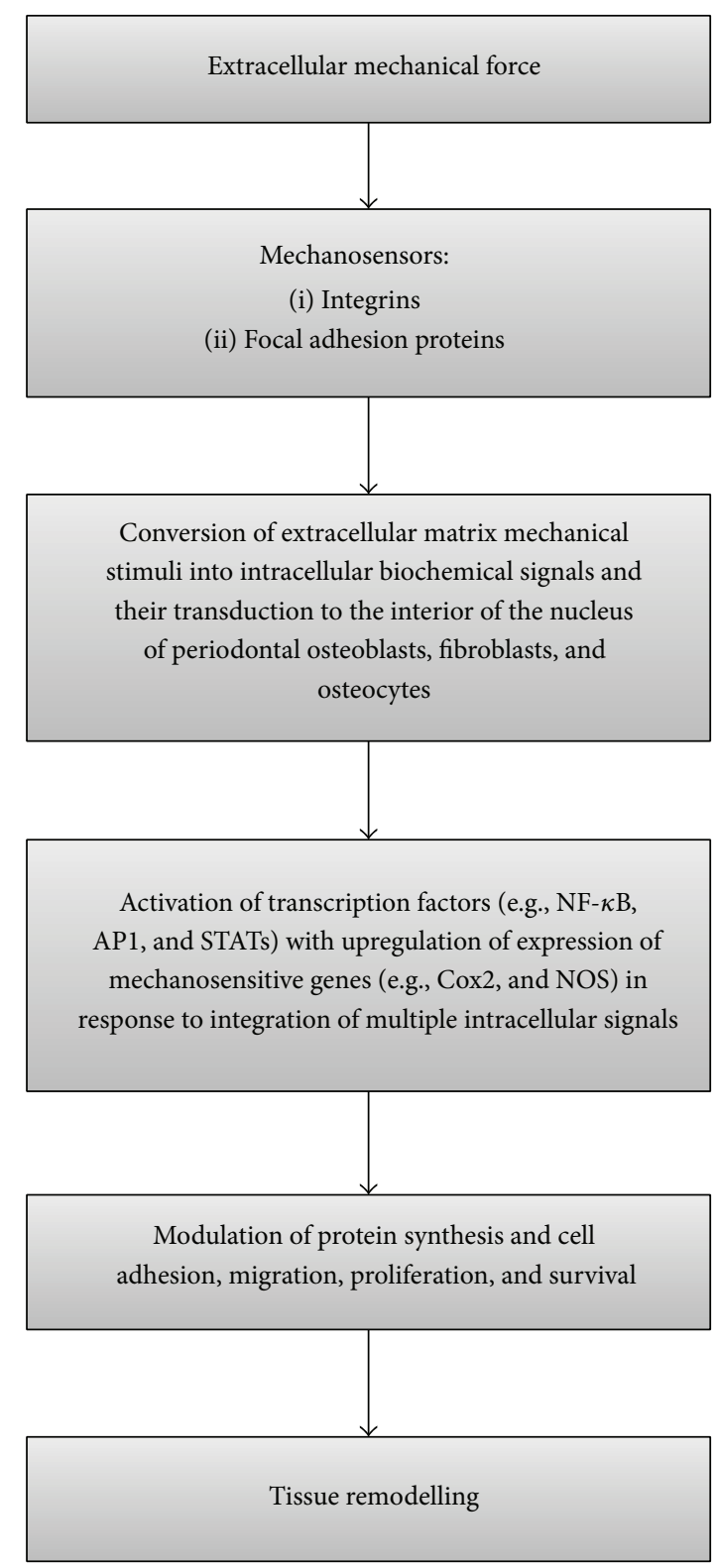

FIGURE 2: Flowchart showing the chain of events from application of mechanical forces to tissue remodelling.

signalling pathways (Figure 3). Furthermore, compression of the cell can cause intranuclear chromatin deformation with dysregulation of the transcriptional machinery and consequent alterations in protein production and secretion $[23,32]$. The nature of the tissue changes will depend on the direction and magnitude of the applied force [39].

The cytoskeleton is connected to the nucleus through outer nuclear membrane proteins, the nesprins (Figure 1). In turn, nesprins interact with inner nuclear membrane proteins such as SUN1, SUN2, and Lamins [32]. Nuclear Lamins, specifically, are a class of intermediate filaments whose function is to support the mechanical integrity of the nucleus [25] and to bind to nuclear DNA, thus constituting the ultimate molecular link for transmission of mechanical load from the extracellular matrix to the nuclear proteins (Figure 1) [32].

\section{Summary}

Mechanotransduction is a complex dynamic process of converting biomechanical stimuli into intracellular biochemical signals eliciting tissue responses. In the local microenvironment of the periodontium, mechanical stresses from application of orthodontic loads cause intracellular changes within the cytoskeleton, configurational changes of extracellular matrix proteins, and the production of proinflammatory cytokines, all of which ultimately mediate bone resorption 


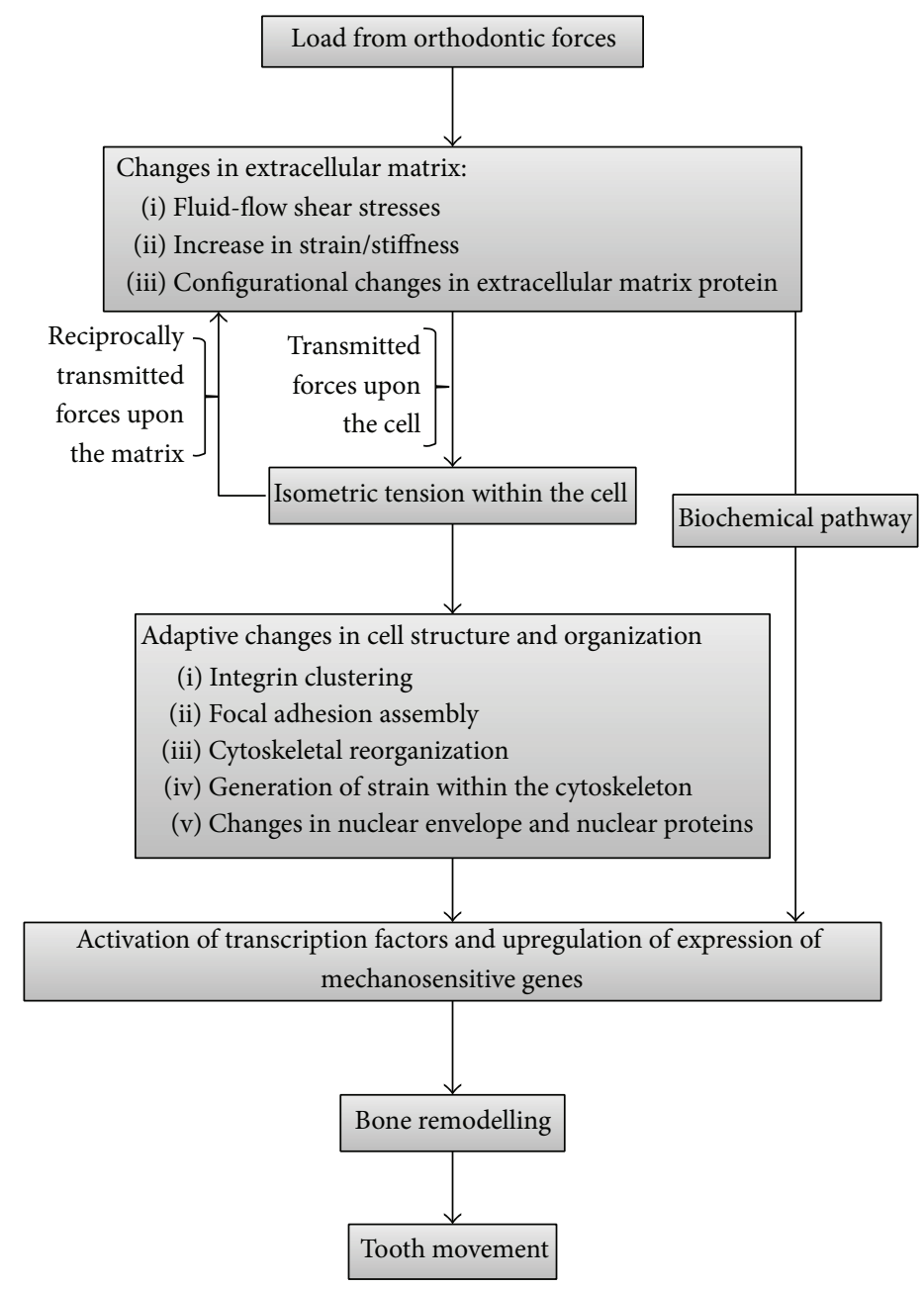

FIGURE 3: Flowchart showing some of the cell-matrix interactions inducing bone remodelling with consequent tooth movement.

and formation, enabling the orthodontic load-induced tooth movement.

\section{Conflict of Interests}

The authors declare that there is no conflict of interests regarding the publication of this paper.

\section{Acknowledgment}

The authors would like to thank Dr. R. Ballyram who created the illustrations that appear in the paper.

\section{References}

[1] T. P. Garlet, U. Coelho, J. S. Silva, and G. P. Garlet, "Cytokine expression pattern in compression and tension sides of the periodontal ligament during orthodontic tooth movement in humans," European Journal of Oral Sciences, vol. 115, no. 5, pp. 355-362, 2007.

[2] P. Zhang, Y. Wu, Z. Jiang, L. Jiang, and B. Fang, "Osteogenic response of mesenchymal stem cells to continuous mechanical strain is dependent on ERK1/2-Runx2 signaling," International Journal of Molecular Medicine, vol. 29, no. 6, pp. 1083-1089, 2012.

[3] P. M. Cattaneo, M. Dalstra, and B. Melsen, "Moment-to-force ratio, center of rotation, and force level: a finite element study predicting their interdependency for simulated orthodontic loading regimens," American Journal of Orthodontics and Dentofacial Orthopedics, vol. 133, no. 5, pp. 681-689, 2008.

[4] S. Henneman, J. W. Von den Hoff, and J. C. Maltha, "Mechanobiology of tooth movement," European Journal of Orthodontics, vol. 30, no. 3, pp. 299-306, 2008.

[5] Š. Sprogar, T. Vaupotic, A. Cör, M. Drevenšek, and G. Drevenšek, "The endothelin system mediates bone modeling in the late stage of orthodontic tooth movement in rats," Bone, vol. 43, no. 4, pp. 740-747, 2008.

[6] F. d'Apuzzo, S. Cappabianca, D. Ciavarella, A. Monsurrò, A. Silvestrini-Biavati, and L. Perillo, "Biomarkers of periodontal tissue remodeling during orthodontic tooth movement in mice and men: overview and clinical relevance," The Scientific World Journal, vol. 2013, Article ID 105873, 8 pages, 2013.

[7] K. Yamamoto, T. Yamamoto, H. Ichioka et al., "Effects of mechanical stress on cytokine production in mandible-derived osteoblasts," Oral Diseases, vol. 17, no. 7, pp. 712-719, 2011. 
[8] H. A. Simon, "Near decomposability and complexity: how a mind resides in a brain," in The Mind, the Brain, and the Complex Adaptive Systems, H. Morowitz and J. L. Singer, Eds., pp. 25-44, Addison-Wesley, Reading, Mass, USA, 1995.

[9] J. L. Singer, "Mental processes and brain architecture: confronting the complex adaptive systems of human thought," in The Mind, the Brain, and the Complex Adaptive Systems, H. Morowitz and J. L. Singer, Eds., pp. 1-9, Addison-Wesley, Reading, Mass, USA, 1995.

[10] J. A. Holland, "Can there be a unified theory of complex adaptive systems," in The Mind, the Brain, and the Complex Adaptive Systems, H. Morowitz and J. L. Singer, Eds., pp. 45-50, Addison-Wesley Publishing Group, Reading, Mass, USA, 1995.

[11] V. Krishnan and Z. Davidovitch, "Cellular, molecular, and tissue-level reactions to orthodontic force," American Journal of Orthodontics and Dentofacial Orthopedics, vol. 129, no. 4, pp. 469.el-469.e32, 2006.

[12] R. S. Masella and M. Meister, "Current concepts in the biology of orthodontic tooth movement," American Journal of Orthodontics and Dentofacial Orthopedics, vol. 129, no. 4, pp. 458-468, 2006.

[13] M. Di Domenico, F. D’Apuzzo, A. Feola et al., "Cytokines and VEGF induction in orthodontic movement in animal models," Journal of Biomedicine and Biotechnology, vol. 2012, Article ID 201689, 4 pages, 2012.

[14] A. Niklas, P. Proff, M. Gosau, and P. Römer, "The role of hypoxia in orthodontic tooth movement," International Journal of Dentistry, vol. 2013, Article ID 841840, 7 pages, 2013.

[15] L. R. Iwasaki, C. S. Gibson, L. D. Crouch, D. B. Marx, J. P. Pandey, and J. C. Nickel, "Speed of tooth movement is related to stress and IL-1 gene polymorphisms," American Journal of Orthodontics and Dentofacial Orthopedics, vol. 130, no. 6, pp. 698.e1-699.e1, 2006.

[16] M. von Böhl, J. C. Maltha, J. W. von den Hoff, and A. M. Kuijpers-Jagtman, "Focal hyalinization during experimental tooth movement in beagle dogs," American Journal of Orthodontics and Dentofacial Orthopedics, vol. 125, no. 5, pp. 615-623, 2004.

[17] P. J. Brooks, D. Nilforoushan, M. F. Manolson, C. A. Simmons, and S.-G. Gong, "Molecular markers of early orthodontic tooth movement," Angle Orthodontist, vol. 79, no. 6, pp. 1108-1113, 2009.

[18] N. A. Meeran, "Cellular response within the periodontal ligament on application of orthodontic forces," Journal of Indian Society of Periodontology, vol. 17, no. 1, pp. 16-20, 2013.

[19] A. Miyagawa, M. Chiba, H. Hayashi, and K. Igarashi, "Compressive force induces VEGF production in periodontal tissues," Journal of Dental Research, vol. 88, no. 8, pp. 752-756, 2009.

[20] P. Rygh, "Elimination of hyalinized periodontal tissues associated with orthodontic tooth movement," Scandinavian Journal of Dental Research, vol. 82, no. 1, pp. 57-73, 1974.

[21] H. C. Wu, Continuum Mechanics and Plasticity, CRC Press, New York, NY, USA, 2005.

[22] C. S. Chen, "Mechanotransduction-a field pulling together?" Journal of Cell Science, vol. 121, part 20, pp. 3285-3292, 2008.

[23] H. Huang, R. D. Kamm, and R. T. Lee, "Cell mechanics and mechanotransduction: pathways, probes, and physiology," The American Journal of Physiology-Cell Physiology, vol. 287, no. 1, pp. C1-C11, 2004.

[24] D. Drasdo and S. Hoehme, "Modelling the impact of granular embedding media, and pulling versus pushing cells on growing cell clones," New Journal of Physics, vol. 14, pp. 1-37, 2012.
[25] D. A. Fletcher and R. D. Mullins, "Cell mechanics and the cytoskeleton," Nature, vol. 463, no. 7280, pp. 485-492, 2010.

[26] S. Suresh, "Biomechanics and biophysics of cancer cells," Acta Biomaterialia, vol. 3, no. 4, pp. 413-438, 2007.

[27] D. E. Discher, P. Janmey, and Y.-L. Wang, "Tissue cells feel and respond to the stiffness of their substrate," Science, vol. 310, no. 5751, pp. 1139-1143, 2005.

[28] K. Anselme, A. Ponche, and M. Bigerelle, "Relative influence of surface topography and surface chemistry on cell response to bone implant materials. Part 2: biological aspects," Proceedings of the Institution of Mechanical Engineers, Part H: Journal of Engineering in Medicine, vol. 224, no. 12, pp. 1487-1507, 2010.

[29] B. Geiger, A. Bershadsky, R. Pankov, and K. M. Yamada, “Transmembrane crosstalk between the extracellular matrix and the cytoskeleton," Nature Reviews Molecular Cell Biology, vol. 2, no. 11, pp. 793-805, 2001.

[30] E. Cukierman, R. Pankov, and K. M. Yamada, "Cell interactions with three-dimensional matrices," Current Opinion in Cell Biology, vol. 14, no. 5, pp. 633-639, 2002.

[31] M. A. Bourdon and E. Ruoslahti, "Tenascin mediates cell attachment through an RGD-dependent receptor," Journal of Cell Biology, vol. 108, no. 3, pp. 1149-1155, 1989.

[32] D. E. Jaalouk and J. Lammerding, "Mechanotransduction gone awry," Nature Reviews Molecular Cell Biology, vol. 10, no. 1, pp. 63-73, 2009.

[33] K. Burridge and K. Wennerberg, "Rho and Rac take center stage," Cell, vol. 116, no. 2, pp. 167-179, 2004.

[34] S. Huang and D. E. Ingber, "Cell tension, matrix mechanics, and cancer development," Cancer Cell, vol. 8, no. 3, pp. 175-176, 2005.

[35] V. Vogel and M. Sheetz, "Local force and geometry sensing regulate cell functions," Nature Reviews Molecular Cell Biology, vol. 7, no. 4, pp. 265-275, 2006.

[36] V. Krishnan and Z. Davidovitch, "On a path to unfolding the biological mechanisms of orthodontic tooth movement," Journal of Dental Research, vol. 88, no. 7, pp. 597-608, 2009.

[37] A. Nanci, "Cytoskeleton, junctions, fibroblasts and extracellular matrix," in Ten Cate's Oral Histology, J. J. Dolan, Ed., pp. 57-78, Mosby Elsevier, St. Louis, Mo, USA, 2008.

[38] Y. T. Huang, Y. Z. Lin, H. L. Wu et al., "Hereditary angioedema: a family study," Asian Pacific Journal of Allergy and Immunology, vol. 23, no. 4, pp. 227-233, 2005.

[39] S. E. Lee, R. D. Kamm, and M. R. K. Mofrad, "Force-induced activation of talin and its possible role in focal adhesion mechanotransduction," Journal of Biomechanics, vol. 40, no. 9, pp. 2096-2106, 2007. 


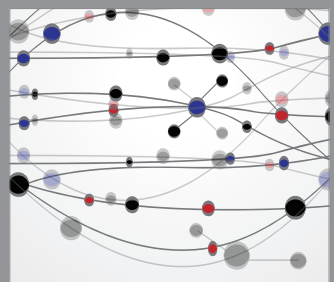

The Scientific World Journal
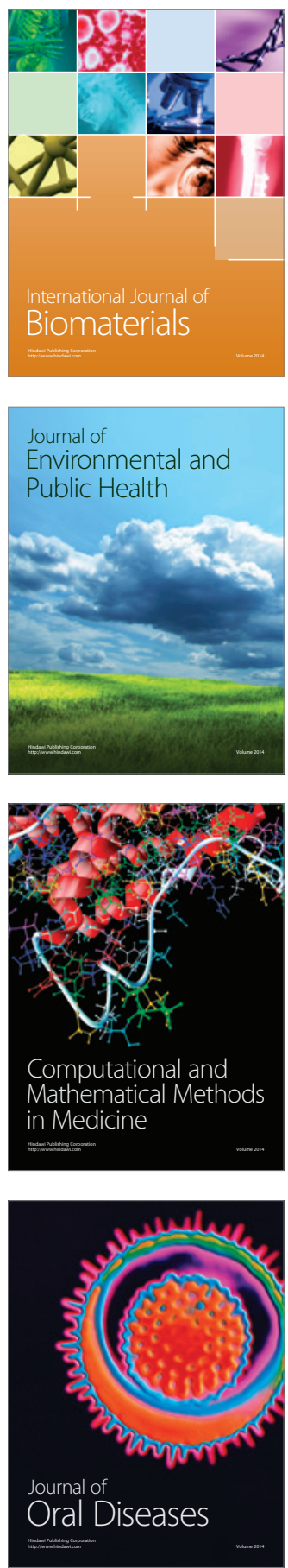
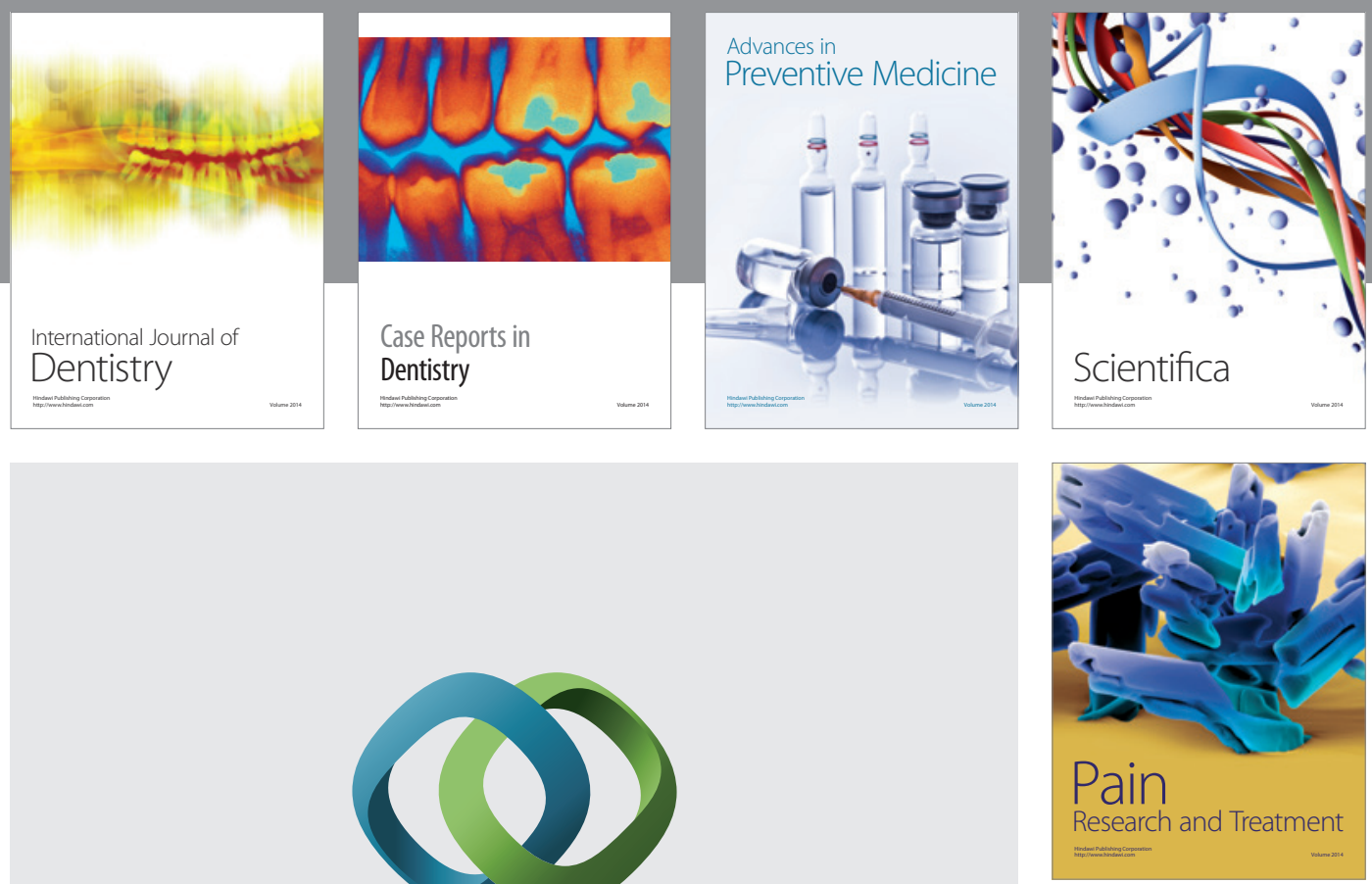

\section{Hindawi}

Submit your manuscripts at

http://www.hindawi.com
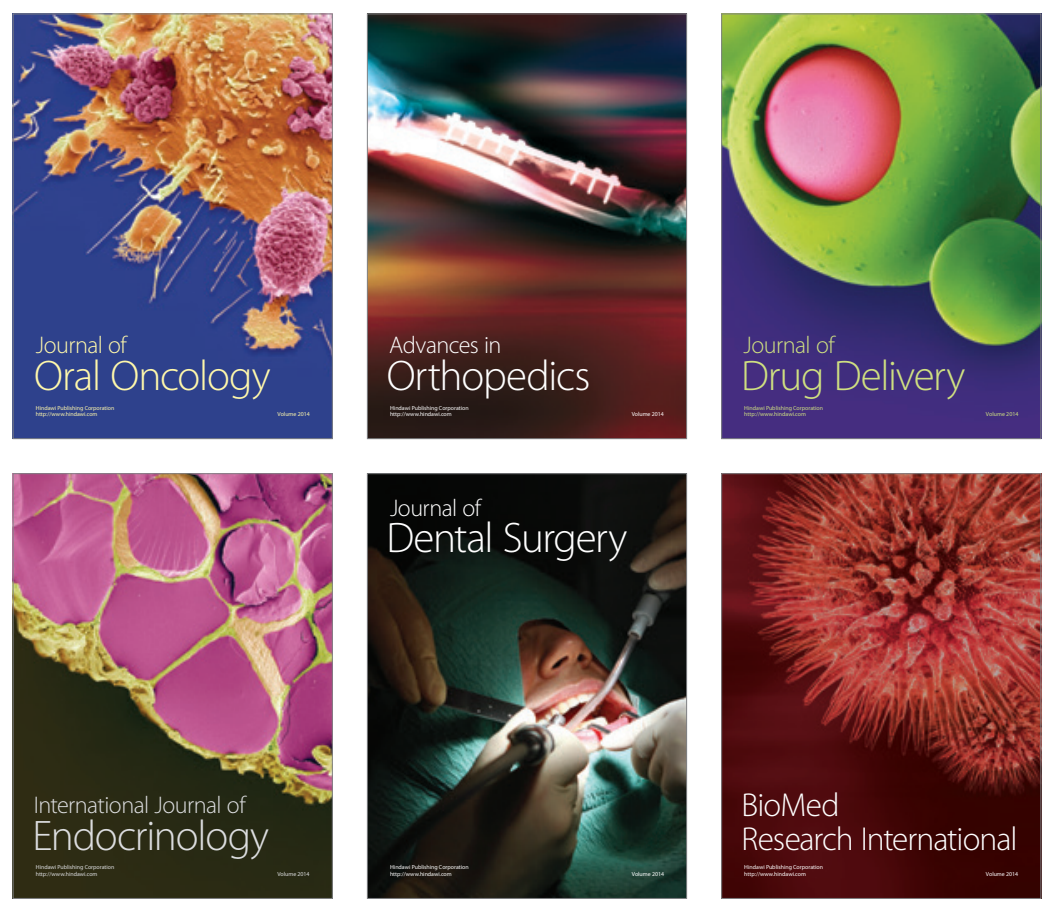

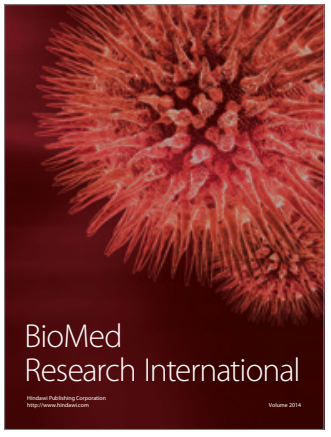

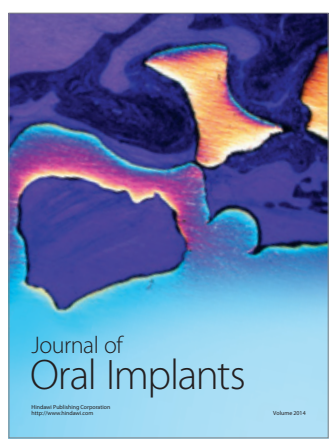
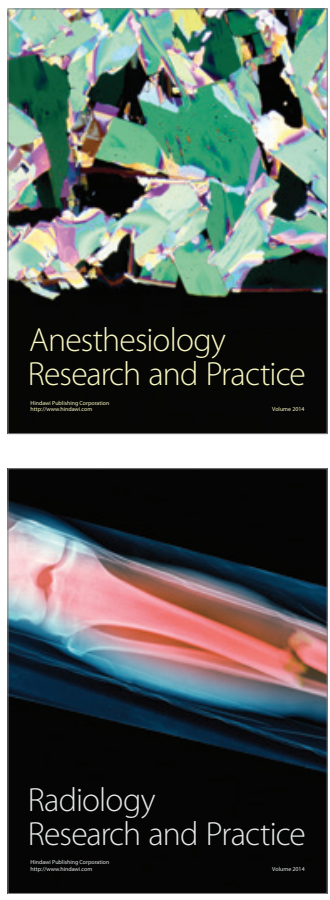